\title{
Educational Corner
}

\section{Excitotoxicity}

Pierluigi Nicotera and Marcel Leist

Chair of Molecular Toxicology, University of Konstanz, Germany

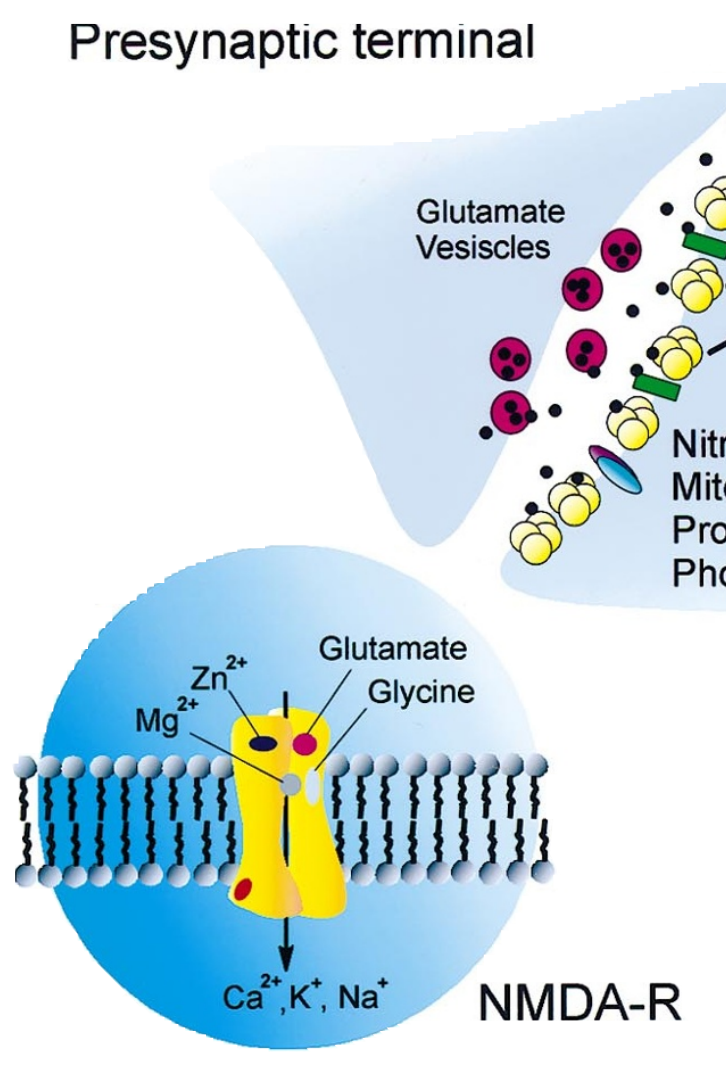

Postsynaptic neuron

@Cell Death Differ., by P. Nicotera and M. Leist

The term excitotoxicity describes the supra-physiological stimulation of excitable cells by excitatory amino acids. The $\mathrm{N}$-methyl-D-aspartate receptor (NMDA-R) is a heteromeric molecule belonging to the class of ionotropic glutamate receptors and it is probably the most important for neuron death. Upon agonist stimulation, this ligand-gated channel opens to $\mathrm{Ca}^{2+}$ and $\mathrm{Na}^{+}$when a potential-controlled $\mathrm{Mg}^{2+}$ block is removed. Other classes of ionotropic glutamate receptors (i.e., kainate or quisqualate) open primarily to $\mathrm{Na}^{+}$and facilitate NMDA-R activation. In acute neurologic diseases, such as stroke and head trauma, excitotoxicity may be related to excessive glutamate release and/or lack of clearance from synaptic clefts, resulting in excessive stimulation of ionotropic glutamate receptors. Due to the prolonged opening of NMDA-Rs, intracellular $\mathrm{Ca}^{2+}$ overload triggers downstream processes resulting in cell death.
NMDA-R

Glutamate non- NMDA-R

Voltage-dependent calcium channel

Glutamate Vesiscles
Nitric Oxide Synthase

Mitochondrial damage

Proteases

Phospholipases
These include mitochondrial damage and the activation of phospholipases, proteases and the $\mathrm{Ca}^{2+}$ - calmodulindependent, nitric oxide synthase (NOS), which generates NO.

\section{Further Reading}

Ankarcrona M, Dypbukt JM, Bonfoco E, Zhivotovsky B, Orrenius S, Lipton SA and Nicotera P (1995) Glutamate-induced neuronal death: a succession of necrosis or apoptosis depending on mitochondrial function. Neuron 15: 961 973

Bonfoco E, Krainc D, Ankarcrona M, Nicotera P and Lipton SA (1995) Apoptosis and necrosis: two distinct events induced respectively by mild and intense insults with NMDA or nitric oxide/superoxide in cortical cell cultures. Proc Natl Acad Sci USA 92: $72162-72166$ 
Excitotoxicity

P Nicotera and M Leist

Choi DW and Rothman SM (1990) The role of glutamate neurotoxicity in hypoxicischemic neuronal death Annu. Rev. Neurosci. 13: 171-182

Coyle JT and Puttfarcken P (1993) Oxidative stress, glutamate, and neurodegenerative disorders. Science 262: 689-95
Lipton SA and Rosenberg PA (1994) Excitatory amino acids as a final common pathway for neurologic disorders. New Engl J Med 330: 613-622 